The Social Structure of Suicide

Author(s): Peter S. Bearman

Source: Sociological Forum, Vol. 6, No. 3 (Sep., 1991), pp. 501-524

Published by: Springer

Stable URL: https://www.jstor.org/stable/684516

Accessed: 25-03-2019 16:00 UTC

JSTOR is a not-for-profit service that helps scholars, researchers, and students discover, use, and build upon a wide range of content in a trusted digital archive. We use information technology and tools to increase productivity and facilitate new forms of scholarship. For more information about JSTOR, please contact support@jstor.org.

Your use of the JSTOR archive indicates your acceptance of the Terms \& Conditions of Use, available at https://about.jstor.org/terms 


\title{
The Social Structure of Suicide ${ }^{1}$
}

\author{
Peter S. Bearman ${ }^{2}$ \\ University of North Carolina at Chapel Hill
}

A parsimonious structural model of the four forms of suicide-egoism, altruism, anomie, and fatalism - defined in Durkheim's Suicide is developed. The model explicitly defines the structural position of each form of suicide by focusing on duality of social structure, while retaining an analytic distinction between social integration and normative regulation. A payoff from this approach is that fatalism and anomie are interpreted in the same framework as altruism and egoism. The result is a consistent account of the four forms of suicide that is faithful to Durkheim's intentions to account for the aggregate suicide rate without recourse to the motivations of actors.

KEY WORDS: suicide; social structure; networks; duality; anomie; fatalism.

\section{INTRODUCTION}

Durkheim argues that the suicide rate is a social fact that can be interpreted as an indicator of social solidarity within a society. One striking feature of the social suicide rate is its stability over time, from year to year showing less variance than the mortality rate (Durkheim, 1897/1951: 49). A central feature of the suicide rate is that it has a structure that is both stable over time and across contexts. We see indication of this structure in the stability of the suicide rate across different categories or groups of persons. Protestants have higher rates of suicide than Jews, entrepreneurs have higher rates than workers, and unmarried men are more likely to kill themselves than those who are married, controlling for age. It is the stability of

\footnotetext{
${ }^{1}$ This paper developed from lectures given in the Social Studies department at Harvard University in 1987.

${ }^{2}$ Department of Sociology, University of North Carolina at Chapel Hill, Chapel Hill, North Carolina 27510.
} 
the suicide rate, both overall and for groups or categories of persons, that allows Durkheim to interpret the suicide rate as an index and proxy for social solidarity (Durkheim, 1897/1951).

A basic sociological insight implicit in Durkheim's work is the recognition that underlying the categorical groups that vary in their relative contribution to the suicide rate are structures of social relations, and that variation in the structure of social relations yields variation in the suicide rate. Thus in his treatment of religious society, for example, he shows that Catholics are distinct from Protestants because they are embedded in a structure of social relations that are Catholic - and that what protects Anglicans from suicide is not rhetoric but the fact that they have Catholic social relations (Durkheim, 1897/1951:152-171). It is the structure of social relations that bind and constrain the individual rather than the beliefs or dogmatic pronouncements of the church that protect individuals from suicide.

This insight is only partially exploited in Durkheim's work. By focusing on the social relations in which people are embedded, Durkheim is able to define "egoism" and "altruism" - two of the four forms of suicide - in purely structural terms. Thus, egoism is defined in the limit as the absence of social relations within a given society, and altruism by the total presence of relations. Egoistic suicide is the suicide of the highly individuated modern man; altruistic suicide is the suicide of the barely individuated man. Problems appear in Durkheim's account of the other two basic forms of suicide - anomie and fatalism. Anomie is characterized by normlessness, yet the social structure of normlessness is not defined. Fatalism is relegated to a footnote and treated as an exceptional case, discussed only because it is logically entailed by the other three forms (Durkheim, 1897/1951:276).

In this paper I develop a purely structural interpretation of Suicide that accounts for the four ideal forms of suicide - anomic, egoistic, altruistic, and fatalistic. The model is consistent with Durkheim's goal of accounting for the suicide rate sociologically - that is, without recourse to the imputation of individual motive - and is consistent with Durkheim's imagery of the etiology for each form. It extends Durkheim in two central ways: First, the model allows for the representation of all four forms of suicide as positions in a social structure. Each type of suicide is associated with a unique pattern of interpersonal and group relations. This allows for a clear distinction between the egoistic and anomic forms of suicide. Second, the proposed model is falsifiable. While it is not likely that individual-level data appropriate for a direct test of the theory will be available, it is possible to evaluate components of the model drawing on extant data. As our interpretation of the social suicide rate rests upon its composition, 
it is possible to suspend many assumptions about the social order and replace them with empirical indicators. The basic payoff is that the approach developed in this paper enables a consistent formal definition of the social structural positions of individuals whose suicides make up the suicide rate.

\section{INTEGRATION AND REGULATION}

Durkheim defines social structure as the intersection of two independent parameters, integration and regulation. Here I define integration as the extent of social relations binding a person or a group to others such that they are exposed to the moral demands of the group. Integration may vary from complete embeddedness in a group - the fully connected clique - to the pure isolate without social relations. Regulation is defined as the normative or moral demands placed on the individual that come with membership in a group. In the ideal, integration and regulation walk hand in hand, with each providing the context through which the other is reproduced. But "abnormal" forms are possible, and an individual can occupy a position that is characterized by high integration and low moral regulation. By extension, whole societies can be abnormal as well, such that the level of integration can be below or above the level of normative regulation. Abnormal social forms are Durkheim's basic concern in The Division of Labor in Society (Durkheim, 1893/1984:291-340).

Concern with the abnormality of the industrial West, which was reflected in the higher suicide rates of developed societies, motivated Durkheim's analysis of suicide as well. But his goals were more ambitious, for in Suicide, Durkheim was concerned both with the structure of individual relations and with the structure of whole societies. In Suicide, Durkheim hoped not only to make sense of the aggregate suicide rate - a task not unlike modeling the increase of restitutive law in the Division of Labor but also to decompose the rate into its constituent parts. He wanted to be able to identify the structural aspects of social positions occupied by persons that subjected them as a category to varying suicidogenetic currents (Durkheim, 1897/1951:323-325). As much of the commentary on Suicide suggests that Durkheim failed to provide an analytically clear distinction between anomie and egoism, one has the sense that he was only partially successful in achieving the second goal (Johnson, 1965; Giddens, 1971; Lukes, 1973; Jones, 1986).

Linking the social and positional levels of analysis in one framework that rests solely on the structural parameters used by Durkheim - regulation and integration - makes it possible to see an analytic distinction between the four forms of suicide. The essential step is to make explicit the 
relationship between individual social position and the macrolevel (societal) integration of groups by focusing on the inherent duality in all tangible social structures.

Duality is a necessary by-product of human social relations. In the social network perspective, our relations with others are constituted by a flow that connects individuals as nodes. Each flow defines a unique relation, a type of tie. Groups of persons are constituted by dense interrelations across one or many ties. Friendship groups, teams, churches, and families are all groups that may be observed empirically. Persons belong to many groups. At the interpersonal level, we are constituted by these relations that we have with others by virtue of our multiple affiliations, that is, by virtue of our membership in families, teams, churches, and cliques. At the macrolevel, persons are flows that connect groups. The fact of interpersonal relations necessarily defines a social structure of group relations. Social structure evidences a duality encompassing the joint constitution of both the group and interpersonal networks in which persons are embedded.

We can represent the four forms of suicide in a two-by-two table as reported in Table I. The rows report integration, here partitioned into two categories, "low" and "high." The columns of Table I report regulation also partitioned as "low" and "high." Thus each cell in the table identifies a unique position defined with respect to integration and regulation. I first consider the off-diagonal cells, egoism and altruism, where integration and regulation are simultaneous, and then move to the abnormal forms of suicide defined by an asymmetry of integration and regulation.

\section{THE OFF-DIAGONAL: FROM MECHANICAL TO ORGANIC SOCIETY}

The ideal typical development of society lies along the off diagonal of Table I, from mechanical society to organic society. Each society is seen to be associated with a characteristic form of suicide, altruism and egoism. Below I focus on ideal-typical structures, and only then turn to the tangible approximations of each ideal in modern society.

\section{Altruistic Suicide and Mechanical Solidarity}

Consider only the ideal-typical mechanical society composed of the replication of homogeneous elements, rather than tangible societies approximating this ideal (Durkheim, 1893/1984:132). In such a context it is 
Table I. Forms of Suicide

\begin{tabular}{lcc}
\hline & \multicolumn{2}{c}{ Regulation } \\
\cline { 2 - 3 } Integration & Low & High \\
\hline High & Anomic & Altruistic \\
Low & Egoistic & Fatalistic \\
\hline
\end{tabular}

awkward to speak of individuals, for each person occupies a position structurally equivalent to the next, that is, one cannot distinguish individuals on the basis of the relations they hold with others. Nor is there the uniquely modern phenomena of personality and consciousness, which appear with the division of labor - the appearance of the chief (Durkheim, 1893/1984: 143). The mechanical society is a society of fully integrated homogeneous nodes, in which each node is either a full member of the group or is out completely. In such a context, integration and regulation are coterminous; all individuals are integrated and all share a common consciousness. According to Durkheim,

For the individual to occupy so little a place in collective life he must be almost completely absorbed in the group and the latter, accordingly, very highly integrated. For the parts to have so little life of their own, the whole must indeed be a compact, continuous mass .... As they consist of few elements, everyone leads the same life; everything is common to all, ideas, feelings, occupations. (1897/1951:220-221)

In the absence of the division of labor, the group combines within itself all of the memberships an individual in the modern world may hold, that is, mechanical society is simultaneously the conjugal, religious, and political society of its members. Since there is but one group to which the equivalent persons belong, it is possible to represent the structure of mechanical society as a fully connected clique. As there is only one group, there is no duality.

\section{Egoistic Suicide and Organic Solidarity}

Whereas the suicide of mechanical society is altruistic, the suicide of organic society is egoistic. Again, consider only the ideal form, rather than real approximations. With the division of labor comes personality, the occupancy of a distinct position in society. As the ideal mechanical society is characterized by pure homogeneity, organic society is characterized by heterogeneity in which the process of individuation associated with modernity has reached its limit. Individual personality is freed from 
the bonds of collective personality, and as all people are unique, nothing social (common) remains to regulate them. Each individual pursues highly individuated ends using others as means. In such a context there is no group to which one could be integrated, and each man or woman is an isolate. It follows that as there are no groups larger than the individual, there is no duality. Organic society, in the limit, is represented as a purely reflexive graph.

This representation of organic society appears to contradict Durkheim's argument that organic solidarity is based, in part, on the functional interdependence of individuals necessitated by the division of labor (Durkheim, 1893/1984:228). Because interdependence is intrinsically relational, social solidarity in organic society is often thought to be a by-product of exchange relations. This line of thought, associated with Spenser, is rejected by Durkheim, who argues that exchange presupposes common norms, and that exchanges in organic society are not the vehicles through which individuals are integrated into the social order. Functional interdependence resulting from the division of labor cannot yield roles. Without a role structure, there are no social relations.

Durkheim's argument is subtle. Recognizing that individuals use exchange relations as means for the achievement of individual ends, Durkheim argues that exchange in organic society will never transcend selfinterest. Consider the simple case of the clothier who exchanges cloth for meat with the butcher. The exchange, and therefore the temporary relation between the two, is necessitated by the division of labor and yields, as a by-product, specialized interdependence. In the ideal, the clothier exchanges cloth with the butcher who offers the best terms of trade. Both parties are insensitive to prior exchanges; each exchange relation appears as an independent trial. Both parties enter the exchange with their ends defined before the relation is formed, and nothing that they do while in the relation shapes these ends. Because the relation fails to expose either to the normative demands of the other, the relation is asocial. Roles as buyer and seller are exchanged and a stable role structure, which implies norms governing action, is not induced from the relation itself (Durkheim, 1893/1984).

In the ideal, organic interdependence will never move beyond these ephemeral and temporary relations that mask self-interest, even if the same parties enter into repeated exchanges, since the terms of trade remain the same. The fact of connectivity entailed by interdependence does not mean that individuals are embedded in social relations - they remain, structurally, egoists.

The importance of a role structure can be easily seen if we imagine that our clothier runs out of cloth and that the butcher, motivated by moral 
sentiments binding him to humanity, ${ }^{3}$ gives the clothier meat as a gift. With the gift, a role structure appears. The butcher is giver, the clothier is taker. Both parties are now exposed to the normative demands of the other, which are attached to the giver and taker roles. The gift is the first truly social relation; each role is possible only by virtue of the other being occupied (Mauss, 1967; Levi-Strauss, 1949). This transformation of the exchange relation is what makes social integration in organic society possible through interdependence. While it is natural for exchange relations under capitalism to be transformed into stable dependency relations, Durkheim argues that it is a mistake to see in the fact of interdependence the basis for solidarity (1984).

Recall that I defined integration as the presence of social relations binding a person to others such that they are exposed, by virtue of the relations, to the normative demands of those to whom they are tied. Functional interdependence resulting from the division of labor does not yield integration beyond that provided by the collective conscience that enables exchange.

\section{Tangible Approximations}

Neither mechanical nor organic society exists as portrayed in the ideal type. The line of social development moves down the off diagonal from mechanical to organic (from altruism to egoism) but nowhere have the extremes of each cell been reached. Tangible social structure lies somewhere in the middle. Yet approximations to each ideal do occur. The mechanical society is an ideal that early bureaucratic social organizations strove to achieve and it is an ideal that underlies most modern armies. The flea market in economic theory is the ideal of the organic society. In the first setting, the social relations of individuals formed in the larger society are stripped away, and the recruits are inserted into and participate in the group as if they had no previous identity. In the flea market, order emerges from pure heterogeneity as buyers and sellers exchange both roles and goods.

For the early bureaucracies, enormous energies were poured into assuring the loss of identity derived from membership in the larger society - especially in conjugal society where people are thought to be most acutely sensitive to particularistic demands. It followed that celibacy was

${ }^{3}$ Durkheim argues that a feeling of "solidarity with humanity" may arise from the frequency of interactions in organic society. Necessarily, the collective sentiments are generalized, and as a result, do not strongly bind individuals normatively. Of course, the butcher who gives away meat on the basis of these sentiments is not going to be a butcher for very long. 
demanded, engineered physically in the beginning, and subsequently through clerical renunciation. Only the socially dead could serve in the bureaucratic order - that is, persons so fully integrated into and regulated by one group that they would ruthlessly adhere to its normative demands (Patterson, 1982).

In the modern army, the same social energies are expended to strip recruits from their earlier identities, and to embed them in the group life. The mechanisms are less dramatic, of course, than those of the early bureaucratic states, but the markers of civil society that report individual personality, for example, hair and clothing style, are removed upon entrance to boot camp. One finds the same insistence on the equivalence of persons within ranks, so that each individual is transposable from one setting to another. Finally, use of collective sanctions guarantees a common normative structure (Heckathorn, 1988; Waller, 1944). Some heterodox religious groups are associated with similar social structures. The modern mechanical societies closely approximate the ideal type, insofar as they simultaneously combine regulation and integration through administrative fiat, totally embedding individuals into one group so that competing normative demands cannot be heard.

Pure heterogeneity, in which there are no groups larger than the individual, such that all relations are instrumental exchanges through which individuals use others to achieve their unique ends, is the limit to which organic society is directed. It is only an analytic fiction, but useful for imagining social structure when regulation and integration are simultaneously absent. The flavor is unattractive, reminiscent of Hannah Arendt's discussion of the structure of loneliness during the Third Reich (Arendt, 1973:478).

\section{DUALITY}

Duality, as an orienting concept in sociology, is most often associated with Georg Simmel (1908/1971), whose imagery of individuals and social circles as jointly defining "distinct levels of social structure which nonetheless mutually constitute one another," can be seen as providing a basic framework in the social network area (Breiger, 1990). But duality is implicit in Durkheim's analysis of suicide as well. Recall that the central idea is that the multiple group affiliations of persons yield at the same moment both a structure of individual relations and a structure of group relations. Real social structures, rather than the ideal images of mechanical and organic societies in which duality is absent because integration and regulation are coterminous, are defined by the intersection of these two levels. This 
imagery associates each of the four forms of suicide to a discrete social position.

\section{An Application of Duality}

Consider a second model of organic society also faithful to Durkheim's imagery in Suicide. Define society as constituted by many groups, each with persons as members. Durkheim refers to these groups as societies, and measures individual integration as integration into conjugal, religious, political, and occupational society. Define individual integration with respect to relations binding an individual to others within a "society." Define social integration as the extent of group to group relations that are a necessary product of the overlap of persons' memberships in named groups. Social integration is dual to individual integration.

To illustrate duality more formally, consider the set of $n \times m$ adjacency matrices reporting the person to group affiliations for mechanical society, organic society, and a fictive modern society, as reported in Table II, part A. Further assume all persons and all groups are represented for each society. Array persons across the rows and groups down the columns of each matrix. Affiliations between persons and groups are reported as a " 1 " in cell $i j$, which indexes the relation between person $i$ and group $j$. Note that the mechanical society may thus be represented by an $n \times 1$ matrix. In contrast, the representation of the ideal-typical organic society would assume the form of a square $(n \times n)$ matrix, each individual is his or her own group, with 1's only on the main diagonal. This follows because, in the absence of social relations, there can be no groups to which individuals belong. The person to group matrix for the hypothetical modern society reports individuals with more than one group affiliation. Multiple group affiliations, or what Simmel would refer to as overlapping social circles, make duality possible.

Label the person to group matrices, as reported in Table II, Part A, the PG matrix. It can be shown, following Breiger (1974), that by ordinary (inner-product) matrix multiplication of the PG matrix and its transpose $\left(\mathrm{PG}^{\mathrm{t}}\right)$ that one yields a person to person matrix. Likewise, ordinary matrix multiplication of ( $\left.{ }^{\mathrm{P}} \mathrm{PG}\right)$ and $\mathrm{PG}$ matrices generates the dual group to group matrix (Breiger, 1974).

Part B reports the interpersonal networks induced from the person to group matrix. Part $\mathrm{C}$ reports the networks for the group to group relations. Neither organic society (ideal) or mechanical society (ideal) evidence duality. Data on relations at either level of society fully account for the structure of social relations at the other. There are no degrees 


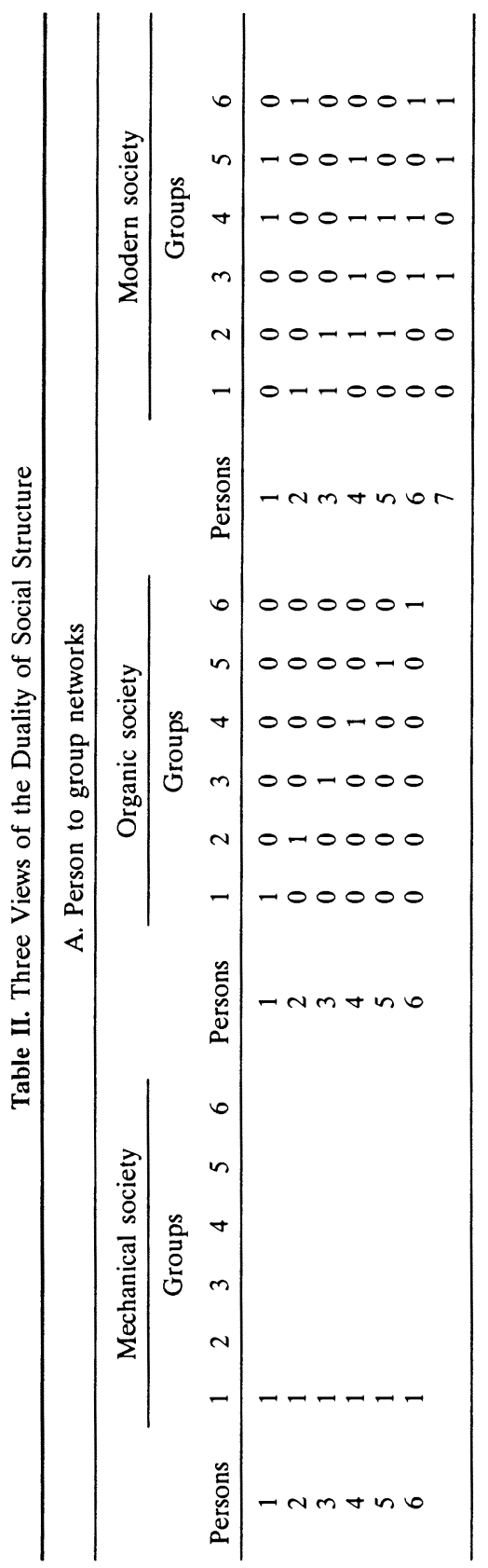



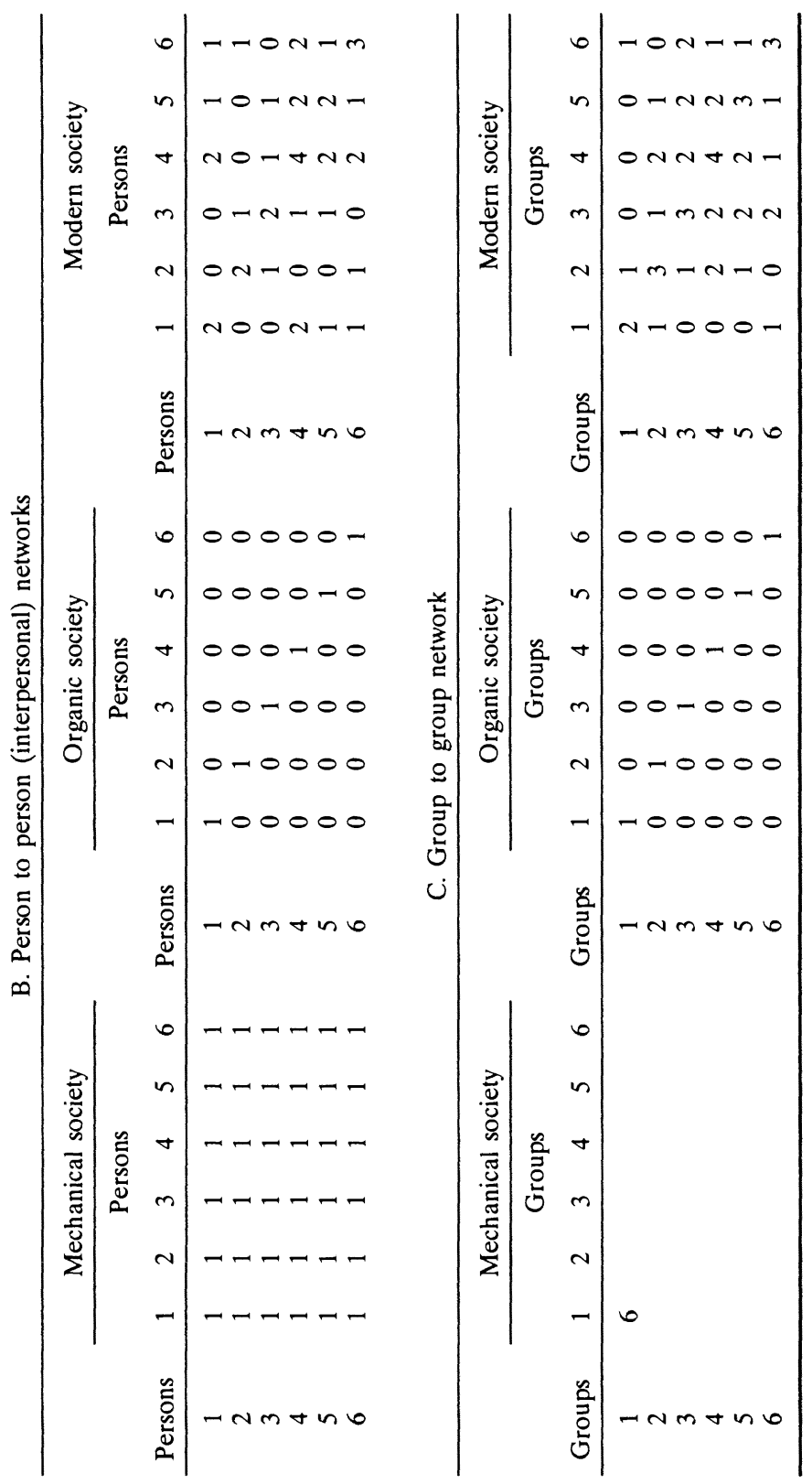
of freedom. On the other hand, information about the structure of personal relations in the fictitious society cannot alone describe the structure of group to group relations. Social integration - the structure of relations between groups - is observably independent of personal integration. Asymmetries in the extent of integration across both levels yield the four structurally unique social positions that are associated with the four forms of suicide.

As persons become more and more individuated, the normative demands and moral regulation placed upon them by virtue of their group memberships decrease proportionally with their involvement in the life of the group. The more groups that an individual belongs to, the less he or she is regulated. While subject to normative regulation of many groups, the highly individuated modern person is freed from constraint and regulation because he or she is involved only marginally in multiple groups, none of which are fully enveloping.

Egoistic suicide is the suicide of the modern world; it is the suicide of the highly individuated person with but weak bonds to others across all of the spheres of social life, what Durkheim labels religious, conjugal, political, and occupational society. Durkheim defines egoism with respect to integration into a single "society," but the ideal egoist is marginally integrated into all societies simultaneously. The ideal egoist is an unmarried middle-aged male protestant professional. The structural position of the egoist is one of low integration and, consequently, low normative regulation.

In the ideal-typical model, for egoistic and for altruistic suicide, integration and regulation are simultaneous. In the case of egoism, the absence of integration prevents moral regulation; for the altruistic suicide, total integration of the individual into the group leads to excessive regulation. In neither instance is duality - where asymmetries in the extent of regulation and integration exist - a core phenomena. Yet it is necessary to see how duality operates for cases where the ideal structure is only an ideal.

\section{THE MAIN DIAGONAL: ANOMIE AND FATALISM AS PATHOLOGICAL FORMS}

The off diagonal, from altruism to egoism, corresponds to the historical movement from mechanical to organic society. In theory this movement is even such that social integration and regulation will be simultaneous. The cell entries on the main diagonal must thus be "pathological," representing conditions for abnormal social context in which regulation has been decoupled from integration. Durkheim refers to these contexts as 
pathological, and views them as deviations from the expected development trajectory.

As egoism and altruism are pure opposites, each condition a reflection of an individual's integration into the social order, anomie and fatalism are also pure opposites, a reflection of the extent to which an individual is regulated by society. Anomie is defined as the social condition of unregulated persons, fatalism is characterized by excessive regulation. Durkheim's imagery is suggested in the two quotations below:

The third sort of suicide, [anomic] results from man's activity lacking regulation
and his consequent sufferings . . .. In anomic suicide, society's influence is lacking
in the basically individual passions, thus leaving them without a check-rein.
(Durkheim, 1897/1951:258)
The above considerations show that there is a type of suicide the opposite of anomic
suicide, just as egoistic and altruistic suicides are opposites. It is the suicide deriving
from excessive regulation, that of persons with futures pitilessly blocked and
passions violently choked by oppressive discipline. It is the suicide of very young
husbands, of the married woman who is childless. So for completeness' sake, we
should set up a fourth suicidal type ... To bring out the ineluctable and inflexible
nature of a rule against which there is no appeal, and in contrast with the expression
"anomy" which has just been used, we might call it fatalistic suicide. (Durkheim,
1897/1951:276)

Durkheim speaks only of regulation in these passages, yet anomie and fatalism, if they are any more than mere rhetorical flourish, must be associated with a unique structural position that can be defined simultaneously by both parameters of social structure - integration and regulation. I define the structural position of both forms below.

\section{Anomic Suicide: High Integration and Low Regulation}

Durkheim defines anomie as normlessness, resulting from the absence of regulation. Implied is that the anomic suicide is the suicide of an individual who is integrated into the social world, for otherwise he or she would be classified as egoists. The necessary condition for anomie is that individuals must be integrated into groups and yet not be regulated by the normative demands of the group. Since membership in groups entails exposure to norms that reside in the group, the anomic position seems contradictory. How is it possible that a person integrated into a society is without moral regulation?

Solving this apparent contradiction is fundamental if we are to preserve the fourfold classification of suicide as reflecting unique social positions. There is no doubt that Durkheim fails in his attempt to adequately specify the structural basis for anomie - that is, normlessness in a context of individual integration. This has led many critics to argue that the egoism 


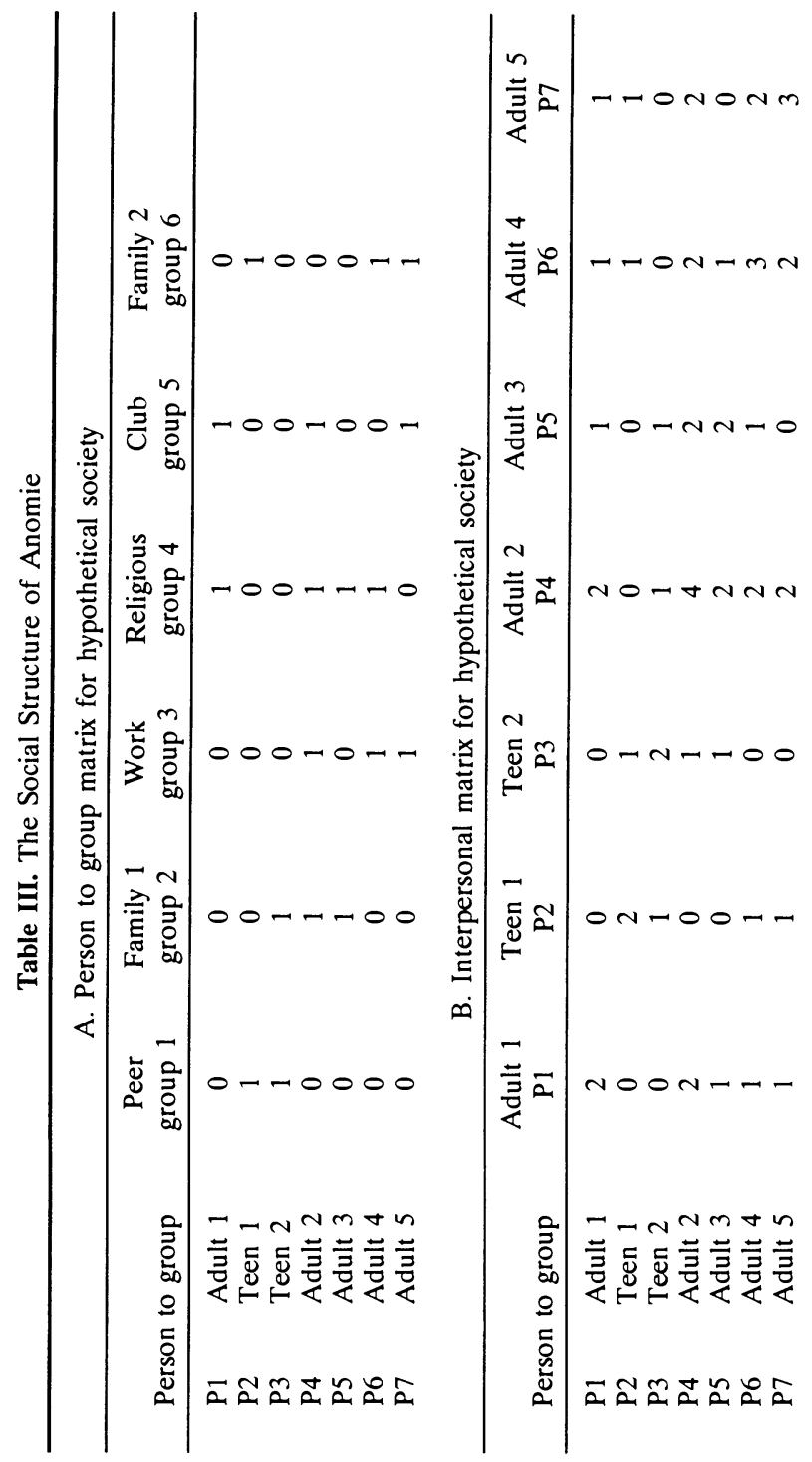




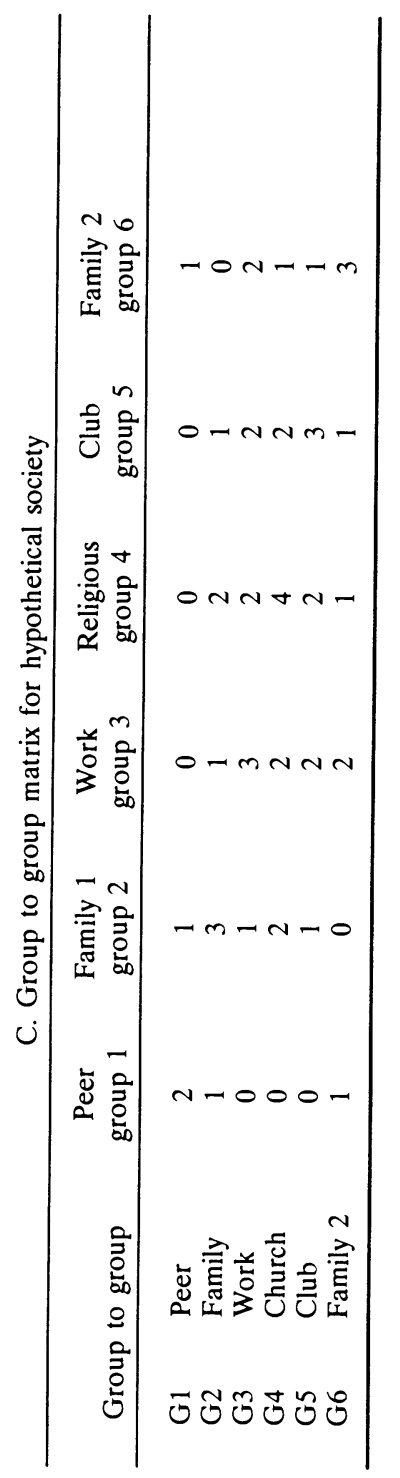




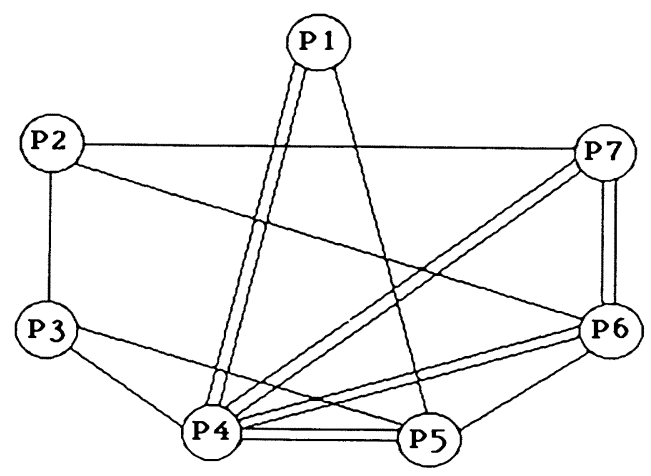

a

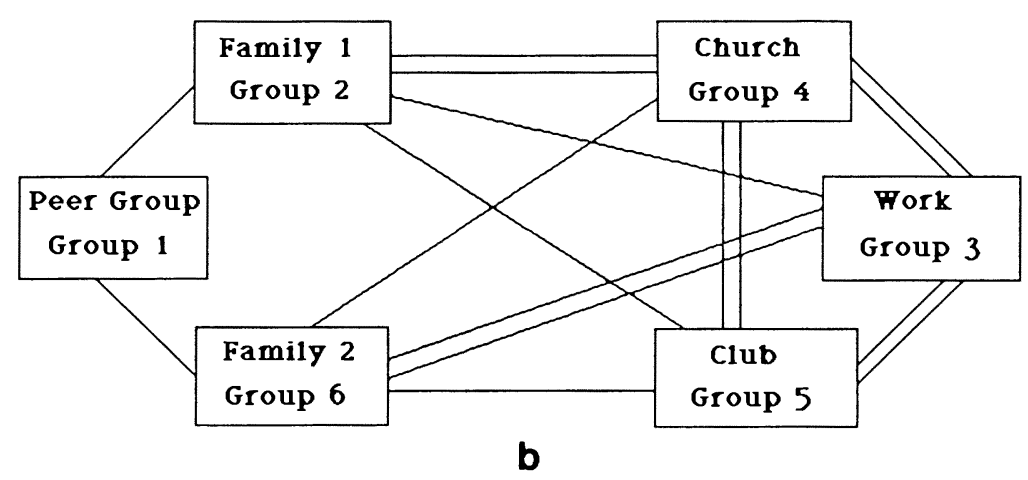

Fig. 1. (a) Graph representation of Table III, Part B. (b) Graph representation of Table III, Part C.

and anomie are the same, both driven by insufficient individual integration into society (Johnson, 1965). It is not necessary to jettison the basic Durkheimian framework to yield a consistent model of suicide; the analytic distinction between egoism and anomie may be retained by focusing on the duality of social structure.

I believe this is implicit in Durkheim's treatment of anomie in Suicide, where he subtly shifts attention away from individual social relations (which define integration), and turns instead to the structure of group relations in society. Durkheim argues that anomie is a psychic condition, experienced by persons living in societies in temporary disequilibrium. Anomic social 
positions are seen as temporary products of crises that disrupt economic and social life. The poor man who suddenly becomes very rich, the farmer who enters the market in times of economic prosperity, and the banker who loses his fortune in depression experience status transitions, which because they occupy a liminal position between their memberships in the old world (which provide moral guidance) and the new (with a competing set of norms) yield dissonance. The social position of the anomic individual is defined not by his or her integration into conjugal, religious, or occupational groups, but by their relations. A bankrupt banker may still belong to the church of the fortunate, but his "co-workers" are the unemployed. The normative values of each world no longer provide a consistent framework for action. Dissonance may be temporary, as individuals struggle to achieve balanced networks by dropping older relations and joining new groups, but the structural position is defined as the occupancy of social groups that are disjoint at the level of social integration. Crises in modern society induce occupants of disjoint groups - and hence anomie as a social condition.

\section{Anomic Social Positions: Adolescence in Modern Society}

Anomie as dissonance resulting from the occupancy of social groups that are disjoint at the level of social integration may be a characteristic position of modern adolescents. The focus is of interest, for the adolescent suicide rate has grown rapidly in recent years, while adolescent suicides were extremely rare when Durkheim wrote Suicide. In contrast to the adolescent of the 19th century, the adolescent of today often spends substantial amounts of time and energy in social worlds quite distant from the adults who have putative moral authority over his or her behavior. The modern adolescent lives for many years in a liminal state, in two worlds that may or may not intersect.

The teen today is often a member of two separate societies, the family of origin and the peer group. In both, the adolescent is integrated, and therefore subject to the normative demands and regulation of each. But the social worlds of the family and the peer group are frequently independent of each other, and the norms governing action and deportment that each society exerts on the teen are, consequently, often experienced as contradictory. Many find it difficult to reconcile the conflicting normative demands entailed by these memberships.

The normative dissonance experienced by the teen is the same as anomie. Just as the lottery winner who is suddenly catapulted out of his world of stable and known norms and expectations that are shaped by social 
relations with others, into the world of the rich (with its own norms governing action), finds himself to be in an anomic state, the teen who is every day embedded in worlds with conflicting expectations and values is cast into an anomic social position. Neither the dissonant nor the anomic may find guidance governing action and desire in the moral regulation of the group. Normative dissonance is a product of the decoupling of the worlds of peers and family. While the teen is integrated into a society, the group to group network of family and peers is segregated, and it is the separation of these two worlds that generates for each the conflicting norms and values to which the individual is subject.

Thus we have the structural position of high integration and low regulation - the individual who is anomic is integrated into groups, but the groups are segregated in the dual network at the level of social integration. The adolescent is especially likely to occupy such a position, relative to others, for dissonance is the product of belonging to few groups, rather than many groups. If people belong to many groups, then the normative influence of each group to which they belong is lessened. Anomie is, in this sense, insufficient individuation in a context of social heterogeneity.

Relabel the rows and columns of the modern society person to group matrix as reported in Table II, part A so that it reports person to group relations for adolescents and adults as in Table III. As before, persons are arrayed across the rows of the matrix while groups are arrayed down the columns. The person to person matrix is shown in part B. The group to group matrix is shown in part $\mathrm{C}$. The associated graph representations of the person to person and group to group matrices are shown in Fig. 1 for ease of presentation.

Consider first the person to group matrix reported in Table III, part A. Persons 2 and 3 are teens, holding memberships in group 1 (a peer group) and families 2 and 6 . Persons $1,4,5$, and 6 and 7 are adults, affiliated with work, church, club, and family groups. Part B reports the person to person network drawn from the person to group matrix. Note from the associated graph representation that all of the individuals are integrated, that is, they are all tied to others in the population. On the other hand, the graph of the group to group network reveals the structural position of anomie. The world of peers and the world of adults are, net of the family ties constituted by the adolescents, radically decoupled.

Assume that norms governing action are shared by individuals who occupy the same social circles. Individuals who bridge social worlds are thus exposed to conflicting norms. Tightly integrated into two social worlds that are decoupled at the level of social integration, the adolescent occupying this contradictory position is subject to the conflicting norms associated with each world. Individuals who are highly integrated into two 
social worlds, such that their dual (group to group) network is segregated, are more likely to feel dissonance than those whose personal networks span multiple groups that are interwoven. Normative dissonance yields normlessness, the absence of regulation, despite integration.

\section{Fatalism}

Durkheim saw that the model of social structure he proposed, completely defined by two independent parameters, integration and regulation, necessarily induced four social positions that would each yield a unique form of suicide. I show that it is simple to represent a fatalistic social position, that the representation I propose fits the examples that Durkheim provides, that it is not difficult to identify other positions in modern society that are structurally equivalent to those Durkheim identifies, and that it is possible to preserve integration and regulation as independent parameters of social structure, by demonstrating that fatalism is a structural position defined by the intersection, in one person, of low integration and high regulation.

Consider Durkheim's examples of fatalistic individuals, the married woman without children and the slave (Durkheim, 1897/1951:276). Focus on the married woman without children, and recall that this is an example more appropriate for the 19th century than it is for today. While tangibly blocked from participation in group life beyond the sphere of domestic society, the woman did not benefit from marriage, which served instead to "aggravate her tendency to suicide" (Durkheim, 1897/1951:189). Children, and not the relationship to the husband, protected the woman against suicide. Durkheim argues that

the fact remains that the family is the essential factor in the immunity of married persons, that is, the family as the whole group of parents and children. Of course since husband and wife are members, they share in producing this result, however not as husband or wife but as father and mother, as functionaries of the family association. (1951:198)

\section{Likewise, the widower suffers}

not because his marriage is ended but because the family which he heads is disorganized.

The departure, not of the wife but of the mother, causes the disaster. (1951:188)

The conjugal relation integrates neither the wife nor the husband fully into domestic society. Men are marginally integrated into domestic society because they are members of multiple groups that define their social identity. The more individuated the husband, the less salient and normatively constraining is his relation to his wife. For the wife, the social relation that binds her into the one group to which she may belong is fictive. 


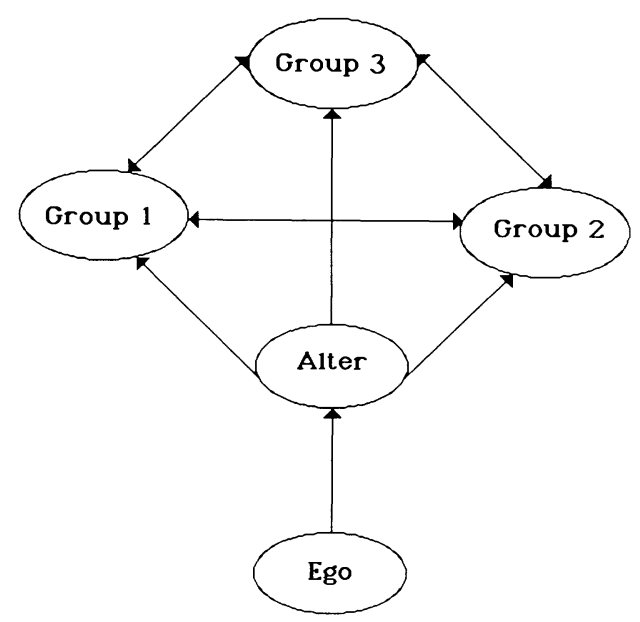

Fig. 2. The structural position of fatalism.

The childless wife does not suffer simply from insufficient integration. Rather she suffers from massive normative regulation resulting from her occupancy of the wife role without independent social identity as a mother. Marginally integrated into conjugal society, she is nonetheless viewed and treated by others as fully integrated. The more affiliations that the husband has, the more a powerful consensual norm governs the behavior of the wife, such that the weaker the conjugal tie, the greater the oppression.

The fatalist has no identity beyond the role that he or she must occupy. The slave has no identity without the master, the married woman without children has no identity without the husband. And yet the wife is without real social ties to the husband and the slave is not integrated into society by his tie to the master. Both are cast adrift without meaningful social ties. Yet their role embeds them in the dense, homogeneous world of their alters' group to group network, which subjects them to the regulation of consensual norms governing their behavior. The more groups in the husband's group to group network, and therefore the weaker the relation to the wife, the greater is the normative constraint that she experiences. ${ }^{4}$

\footnotetext{
${ }^{4}$ There is logically a threshold that determines fatalism. For example, if the husband's group affiliations are very diffuse, the sentiments held by all the members will be generalized and consequently lack moral force. On the other hand, if the husband's affiliations are narrow, the effect of group cohesion, however strong, on the wife should be less.
} 


\section{Reproduction of Fatalism}

The exchange relations of organic society tend naturally, as a result of their conflictual base, to be transformed into social relations of dependence. The disjoint group network of the anomic tends naturally to revert to balance, as persons strive to reduce dissonance, by dropping group relations that they experience as contradictory. Egoism and anomie are, in this sense, positions in a social structure that are inherently unstable. An interesting property of fatalism is that it induces in the fatalist behaviors that reproduce, rather than transform, their position.

By striving to be integrated into conjugal society, the wife without children serves only to accentuate others' perceptions of her as integrated, without a corresponding change in the inherent asymmetry of the conjugal relation. Her efforts to secure a tie to her husband enslave her further to the ideals of others.

A similar position is occupied by those on the periphery of a clique where the failed efforts to secure a role within the group induce others to believe the individual is integrated. Consider the youth, striving to gain acceptance from those in the center of a clique, by adopting the behaviors and the deportment of the leaders whose position rests on their ability to redefine the standards necessary for membership. At the precise moment the peripheral member appropriates the latest style, it slides out of fashion to be replaced by a new innovation. Persons on the inside of the clique know who is in and who is out - and when those who are out act "in," being "in" is redefined. Yet persons not in the clique are unaware of the fine distinctions that govern being in or being out, precisely because of the concerted efforts of those on the periphery to gain acceptance. Their efforts succeed only in enslaving themselves to a normative ideal that is, like that of the childless wife, fictive, because it is not sustained by an actual social relation.

In both instances the structural position is the same: the fatalist occupies the position of a peripheral member within one social group, such that others believe he or she occupies a fixed role and orient their relations with the fatalist as if that role was tangibly occupied. Fatalism is a structural position induced by the asymmetry of individual integration and group integration. This position yields an asymmetry in perception. Fatalists are governed by the formal occupancy of a role. In the eyes of others they have identity only as a role occupant. In their own eyes they are without social ties and therefore purpose. Fatalists do not derive protection from the role, for it comes to them from the outside. The role, but not the individual who occupies it, is reproduced by the others that surround him or her. 
If the group to group network in which the fatalist's alter is embedded is cohesive, the resulting asymmetry in the primary tie will be large, and the constraint that the fatalist experiences correspondingly more powerful. We can represent this position as a graph as in Fig. 2.

\section{DISCUSSION}

The ideal typical development of human societies lies along the diagonal from mechanical to organic society. Each ideal has its characteristic form of suicide. In both, the twin dimensions of social structure integration and regulation - walk hand in hand. They are simultaneous. The path of social development may be interrupted and pathological forms may appear. These forms are characterized by the decoupling of regulation and integration. At the individual level, this decoupling is experienced as anomie or fatalism. The anomic social condition is marked by the asymmetry between individuation (low) and social heterogeneity. Individuals occupying an anomic social position are thus integrated, but only marginally regulated. On the other extreme, individuals occupying a fatalistic position are confronted with massive regulation in a context of individual isolation.

For years, sociologists have worked hard to preserve a basic Durkheimian insight - that the collective life of the group is a function of the density and multiplexity of social relations that serve to bind individuals into a world larger than themselves. In doing so, many have rejected an important Durkheimian insight: in abnormal contexts, integration and regulation are not isomorphic. These abnormal contexts are evidence of a decoupling of the group and individual levels of society. Persons may be integrated, yet be subject to dissonance and normlessness because the groups that they belong to are disjoint. Likewise, individuals may be subject to constraint despite the fact that they are not integrated. Both asymmetries arise from duality, a measurable aspect of all social structure.

It is highly unlikely that we will ever have access to data that can properly test the representation of each form proposed above. On the other hand, we already have data that can be used to evaluate central components of the model at the social rather than the individual level. Survey-based ego-centered network data can be used to estimate the extent to which persons assigned $a$ priori to groups differ with respect to group to group integration. Mixing matrices similar to those currently employed in the study of disease transmission are natural avenues for identifying the attributes of persons who occupy bridge positions 
between social worlds and thus are likely to experience dissonance (Sattenspiel, 1990; Anderson et al., 1990). Likewise, saturation sampling of relatively large populations - schools and neighborhoods, for example - has been proposed as a technique for measuring individual integration into both interpersonal and group networks. (Rindfuss et al., 1988). Simultaneous analyses of both levels of social structure allow researchers to identify the distribution of fatalistic and anomic positions by attributes of persons.

Insight into the social structure of suicide is derived from the explicit recognition of the duality of social structure that yields social positions defined by the intersection of the interpersonal networks of individuals and the group networks to which they give rise.

\section{ACKNOWLEDGMENTS}

I thank Harrison White and Everett Wilson for their insightful comments on earlier drafts of this paper. I am also grateful for the comments of the anonymous referees.

\section{REFERENCES}

Anderson, R. M., S. Gupta, and W. Ng

1990 "The significance of sexual partner contact networks for the transmission dynamics of HIV." Journal of Acquired Immune Deficiency Syndromes 33:417- 419.

Arendt, Hannah

1973 The Origins of Totalitarianism. New York: Harcourt Brace and Jovanovich.

Breiger, Ronald

1974 "The duality of persons and groups." Social Forces 53:181-190.

1990 "Social control and social networks, a model from Georg Simmel." In Craig Calhoun, Marshall W. Meyer, and W. Richard Scott (eds.), Structures of Power and Constraint: Papers in Honor of Peter M. Blau. Cambridge: Cambridge University Press: p. $453-476$.

Durkheim, Emile

1951 Suicide: A Study in Sociology. (1897*) New York: Free Press.

1984 The Division of Labor in Society. (1893*) New York: Free Press.
Giddens, Anthony

1971 Capitalism and Modern Social Theory: An Analysis of the Writings of Marx Durkheim and Max Weber. London: Cambridge University Press.

Heckathorn, Douglas

1988 "Collective Sanctions and the Creation of Prisoner's Dilemma Norms." American Journal of Sociology 94:535-562.

Johnson, Barclay

1965 "Durkheim's one cause of suicide." American Sociological Review 30:865- 886.

Jones, Robert A.

1986 Emile Durkheim: An Introduction to Four Major Works. Beverly Hills, CA: Sage Publications.

Levi-Strauss, Claude

1969 The Elementary Structures of Kinship. Boston: Beacon.

Lukes, Steven

1973 Emile Durkheim, His Life and Work: A Historical and Critical Study. London: Penguin Books. 
Mauss, Marcel

1967 The Gift. New York: Norton.

Patterson, Orlando

1982 Slavery and Social Death. Cambridge, MA: Harvard University Press.

Rindfuss, Ronald, J. R. Udry, Barbara

Entwisle, and Peter S. Bearman

1988 "Risk behaviors for AIDS and Pregnancy in Adolescents." NICHD grant proposal.

\section{Sattenspiel, Lisa}

1990 "Modeling the spread of infectious disease in human populations." Yearbook of Physical Anthropology 33: in press.

Simmel, Georg

1971 On Individuality and Social Forms. (1908*)

Waller, Willard Chicago: Chicago University Press.

1944 The Veteran Comes Back. New York: Dryden Press.

*Original publication date. 